\title{
A Holistic Approach to Educational Servicescape: An Abstract
}

\author{
Nina Krey, Joanne T. Cao, and Jennifer A. Espinosa
}

\begin{abstract}
Traditionally, multiple studies have examined the influence of classroom environments on student behavior and academic performance. However, considering that an average student spends $12-15 \mathrm{~h}$ a week in a classroom setting, additional environments should also be considered when assessing students' academic success. Given the service nature of education, this study draws from the servicescape framework to examine the influence of environmental stimuli in the academic learning environment. Specifically, diverging research streams drive the conceptualization of a new framework of the transformative educational servicescape. Thus, we propose four distinct environmental dimensions - physical, social, socially symbolic, and natural - that impact the servicescape and, subsequently, students' academic success. As such, this article offers educators insights to an optimal educational servicescape beyond classrooms by implementing a holistic approach to student academic performance.
\end{abstract}

References Available Upon Request

\footnotetext{
N. Krey $(\triangle) \cdot$ J.A. Espinosa

Rowan University, Glassboro, NJ, USA

e-mail: krey@rowan.edu; espinosaj@rowan.edu

J.T. Cao

University of Southern Mississippi, Hattiesburg, MS, USA

e-mail: joanne.cao@usm.edu
} 